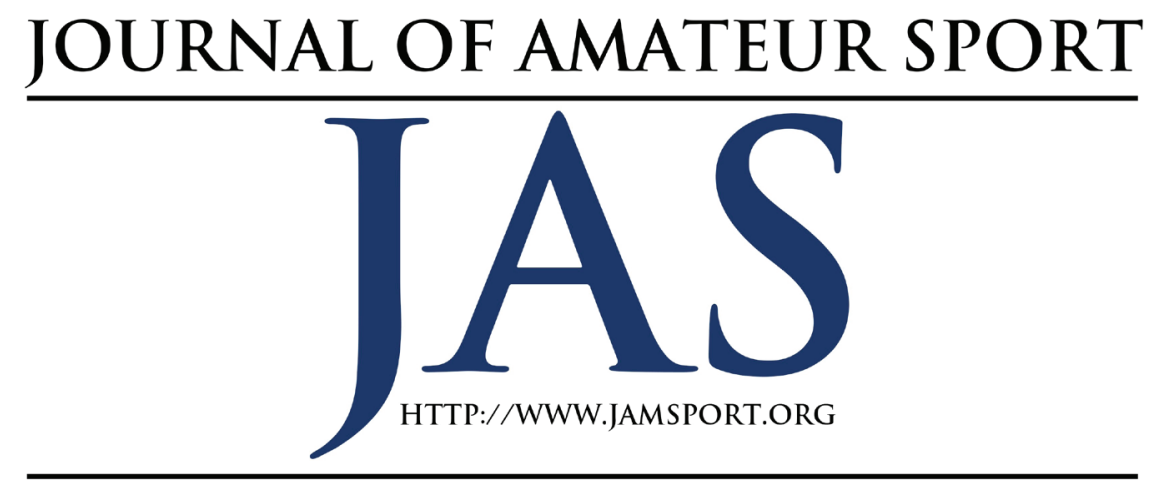

\title{
Examining Differential Coaching Behaviors in Positive Coaches: A Mixed-Methods Perspective Guided by the Expectation Performance Process
}

\author{
Megan Buning
}

Augusta University

\begin{abstract}
The purpose of this concurrent triangulation mixed-methods study was to examine differences in perceptions of coach behaviors of athletes of varying performance abilities situated within a self-fulfilling prophecy. The mixed-methods approach allowed for a more holistic examination of softball athletes' perspectives of head coaching behaviors. Division I softball athletes $(n=148)$ completed the CBAS-PBS providing perceptions of head coach $(n=20)$ behavior. Coaches rated each athlete using the MERS providing a performance expectation score. Thirty-eight athletes provided supporting perspectives through individual interviews on perceptions of differential treatment based on expected performance level. Cluster analysis produced low, average, and high expectancy groups. MANOVA and DFA revealed two underlying functions that distinguished between groups. High expectancy athletes experienced less 'detached' coaching behaviors than low or average athletes. Qualitatively, athletes provided examples that support quantitative results that teammates perceive lower rated athletes are treated differently.
\end{abstract}

Key Words: self-fulfilling prophecy, female athletes, differential treatment

O elf-fulfilling prophecies (SFP) are evident in all types of environments from the classroom, workforce, military, medical field, and the sports arena (Davidson \& Eden, 2000; Inamori \& Analoui, 2010; McNatt, 2000; Rowe \& O’Brien, 2002; Wilkinson,
2009). However, much of what we know about SFP's are created under experimental conditions. Prophecies can have positive outcomes by enhancing receiver performance but can also have negative outcomes resulting in weakened receiver performance (Davidson \& Eden, 2000; 
Rowe \& O’Brien, 2002). Horn, Lox, and Labrador (1998) introduced the expectation-performance process (EPP) detailing a SFP within sports. Years of personal experience have exposed the reality of the EPP. However, both experience and literature have revealed positive athlete outcomes facilitated by educated coaches that either facilitate or terminate a SFP within teams. Exceptional coaches learn how to approach athletes as individuals in terms of motivation and feedback, have flexible expectations, and consistently communicate both individual and team expectations despite performance expectations (Becker \& Wrisberg, 2008; Bloom, Crumpton, \& Anderson, 1999; Kahan, 1999).

Coaches do form expectations about athletes' performance ability based on different types of cues (Solomon, 2008a; 2010), and do change behaviors based on these expectations (Amorose \& Wiess, 1998; Horn et al., 1998; Solomon, DiMarco, Ohlson, \& Reece, 1998a; Solomon $\&$ Rhea, 2008). If perceived negatively, behaviors can be harmful to the athlete's performance, continued enjoyment, persistence, and overall motivation level to continuing playing (Amorose, 2003; Horn, Lox, \& Labrador, 2006; Lyle, 1999; Smith, Ntoumanis, \& Duda, 2010). It is startling that many coaches are unaware or unrealistic about the behavior they display toward their athletes (Smith et al., 2010; Smith \& Smoll, 2002). The focus around coaching behavior has shifted from the influence of behaviors to the elements of a healthy coach-athlete re- lationship (Jowett \& Cramer, 2010) resulting in missed opportunities to make coaches aware of their behavior, influences, and prophecies. Situated within the context of a SFP, the purpose of this study was to examine if collegiate softball athletes with a quantifiable coach-assigned performance expectation score perceived various coaching behaviors differently. The mixed-methods approach of this study will enhance the literature about coach expectations and provide additional understanding about the expectation performance process. Additionally, the goal is to provide further insight into a how female softball athletes perceive coaching behaviors in an effort to provide information to enhance coach training and education.

\section{The Prophecies}

The SFP was unintentionally discovered in early experimental laboratory research (Clark, 1927; Merton, 1948; Rice, 1929), and has been used to explain a wide variety of social problems ranging from high-achiever performance to managers' influence on employee performance to teachers' impact on students (Gladwell, 2008; Jussim \& Harber, 2005; Jussim, Palumbo, Chatman, Madon, \& Smith, 2000; Nantanovich \& Eden, 2008). Popular definition of an SFP contends the cycle starts with an inaccurate or strong belief about a person or situation, followed by actions that reflects the belief, and results in the receiver changing behavior to reflect the belief (Merton, 1948; Salomon, 1981). An example 
within the sport environment could be a coach expecting an athlete to be a top performer based on a skills video posted online. In reality, the athlete may be an average-level athlete. When the athlete attends the coach's camp, the coach treats the athlete as if he or she is the most highly skilled athlete at the camp (e.g., gives the athlete the most challenging tasks, uses the athlete as a demonstrator for skill performance). As a result, the athlete changes his or her approach to drills during camp (e.g., gives more effort, increases concentration) and emerges as the "best" athlete at camp.

A self-sustaining prophecy works slightly differently than a SFP. Self-sustaining prophecies begin similarly but progress differently. For a self-sustaining prophecy, once the person responds to the receiver based off the initial expectation, the person's behavior then reinforces receiver behavior and causes the receiver to maintain, rather than alter, existing behavior. Self-sustaining prophecies are much harder to detect because there is not a striking change in behavior. Using a similar example as above, a coach finds a skill video posted online of the athlete that is registered to attend an upcoming camp. The video shows the athlete performing skills on a day when the athlete was later diagnosed with the flu resulting in average to below average performance captured on the video. However, when healthy, the athlete has a reputation for being one of the most highly skilled athletes in the area. Later, when the athlete (now healthy) attends the coach's camp, the coach treats the athlete indifferently (e.g., does not pay much attention to the athlete, does not give the athlete challenging tasks) because the coach formed an expectation about the athlete's performance based on the previously viewed skills video. The athlete does not see the point in exerting more effort and maintains the same amount of effort during the camp resulting in average to below average performance during the camp. Salomon (1981) details the existing behavior is what the person observed in the initial observation even if the behavior is not typical behavior. Researchers argue self-sustaining prophecies occur more often and realistically than SFP's in the natural environment (Eden, 1990, 2016; Rowe \& O’Brein, 2002; Rudman \& Glick, 2008; Salomon, 1981).

Positive prophecies occur if the belief about the receiver is desirable resulting in a positive outcome, but prophecies tend to have a negative connotation. The prophecy became of particular interest with the submission of Rosenthal and Jacobson's (1968) landmark experimental study of a SFP in the classroom (i.e., the Pygmalion effect) where they demonstrated a SFP through positive student outcomes connected to deception-induced higher teacher expectations. However, this study also revealed what could have been considered a negative prophecy, the Golem effect. The Golem effect is characterized by low performance expectations from the leader resulting in poor performance from the receiver. Studies on the Golem 
effect are scarce because of the negative outcomes produced; however, Eden (1990) presents the argument that naturally occurring Golem effects occur more often than naturally occurring Pygmalion effects. Despite evidence of the SFP, many critics argued these types of experiments were unethical, controversial, did not show a large effect, and contained methodological flaws (Eden, 2002; Jussim \& Harber, 2005; White \& Locke, 2000). A few researchers have attempted to use a SFP to shape positive outcomes (Chadha \& Narula, 2016; Reynolds, 2007), but most of the Pygmalion research and training has been implemented in the management setting with leader behavior (Eden, 2002, 2016; Eden et al., 2000; Tierney \& Farmer, 2004). Different effects are recognized to occur in sports (Hancock, Adler, \& Côté, 2013; Horn, Lox, \& Labrador, 2006), however, no literature was found to show intentional training for sport coaches. McNatt's (2000) review of the Pygmalion effect across a variety of settings indicates the effect can be strong and should be taken into consideration for those in leadership positions.

Research on SFP's has continued with teachers and students (Jussim \& Harbor, 2005; Rist, 2000; Reynolds, 2007; Smith, Jussim, \& Eccles, 1999), medical professionals and patient outcomes (Christakis, 1999; Meyer et al., 2002; Wilkinson, 2009), managers and employees (Davidson \& Eden, 2000; Eden, 2002; McNatt, 2000; Natanovich \& Eden, 2008), and military instructors and trainees (Eden
\& Shani, 1982; McNatt, 2000) showing the same type of effect. The literature is unclear as to how much of the effect is a result of a self-fulfilling versus a self-sustaining prophecy. Prophecies have the power to increase the chance of a result that would otherwise be a low-chance outcome stemming from the initial belief (Wilkinson, 2009).

Within athletics, no research was found examining self-sustaining prophecies in sports, and limited current research was found on the SFP specifically (Siekanska, Blecharz, \& Wojtowicz, 2013; Horn, Lox, \& Labrador, 1998; Solomon, Golden, Ciapponi, \& Martin, 1998b; Weaver, Moses, \& Snyder, 2016). Sport researchers have pulled knowledge about prophecies primarily from early literature pertaining to teacher expectations (McNatt, 2000; Rowe \& O’Brien, 2002; Reynolds, 2007) and the management field (Davidson \& Eden, 2000; Eden, 1990; Inamori \& Analoui, 2010). Horn et al.s (1998) expectation performance process is the most commonly used process within athletics used to illustrate a SFP.

\section{Expectation-performance process (EPP)}

One version of an SFP that has been adapted to fit sports to educate coaches on how they can affect an athlete's development is the four-step cycle called the expectation-performance process (EPP, Horn et al., 1998). Step one, the coach uses impression cues to develop an expectation (accurate or inaccurate) for an athlete's predicted athletic perfor- 
mance and behavior (Horn et al., 2006; Solomon, 2010). Flexible expectations do not create adversity (Becker \& Wrisberg, 2008; Wilson \& Stephens, 2005), but inflexible, inaccurate expectations cause issues (Horn et al., 1998). The coach may not see the actual performance ability of the athlete, and the incorrect expectation can alter the way the coach responds or reacts to that particular athlete. If this occurs, then coach and the athlete move into the second step of the cycle.

Step two is the most researched step in the EPP (Solomon, 2010). Step two of the EPP outlines that a coach who differentiates behavior changes the frequency and quality of interactions with the athlete (Horn et al., 1998). Coaches develop expectations about athletes' potential performance ability, and they group athletes intentionally or subconsciously into high ability or low expectation groups. Athletes perceived to be low expectancy athletes may receive less interpersonal contact social or skill-related than high expectancy athletes, and high expectancy athletes may receive more interpersonal contact and more approachable behaviors (for example smiling, personal contact). An even more hazardous behavior change could occur if the coach spends less time or provides poorer quality of skill information or instruction to the low expectancy athletes. The coach may even reduce the amount of time low expectancy athletes are allowed to practice drills, and the coach may be less persistent in helping these athletes succeed past a drill. As a result, practice quality and amount of instruction is consistently unequal. Although youth sport studies have returned inconsistent results (Amorose \& Weiss, 1998; Horn, 1984; Solomon, 2008b; Solomon et al., 1998b), high expectancy athletes have been observed receiving overall more and higher quality feedback then their lower expectancy counterparts in elite athletics (Sinclair \& Vealy, 1989), high school athletics (Solomon et al., 1998b, 2008a), and in college athletics (Buning, 2016; Solomon, 2008a; Solomon \& Kosmitzki, 1996). Consistent differential treatment that alters athletes' behaviors in ways that limit athletes' abilities or opportunities to learn lead to damaged coach-athlete communication and to the third step in the EPP cycle (Horn et al., 1998).

Step three involves the coach's expectancy-based treatment of the athlete affecting the athlete's performance and psychological growth. If a coach is consistently giving high expectancy athletes more and high-quality interactions (e.g., more time, feedback, instruction, and practice), then they should be able to capitalize on their situation toward the advancement of their athletic performance. Conversely, if low expectancy athletes repeatedly receive less, and poorer quality interactions, then they may not show the same amount of skill improvement as high expectancy athletes (Horn et al., 1998). In this situation the coach attributes the skill differences between the two types of expectancy athletes as natural, inherent differences rather than differences brought about from differen- 
tial treatment. The observable disparity in the coach's behavior toward the two types of athletes indicates the coach's original expectations about the athletes' performance ability may not only predict but determine the level of success the athletes' will achieve (i.e., self-fulfilling prophecy).

A coach's biased feedback behavior can create negative outcomes in skill development, rate of learning, and achievement level within expectancy groups, but differential behavior can have more meaningful negative effects on psychological growth (Horn et al., 1998). Research on differential coaching behavior and the impact on athletes' psychological maturation have revealed causes or changes in athletes' self-concept (Smith \& Smoll, 1990, 2002; Smith, Smoll, \& Barnett, 1995), perceived competence (Amorose \& Horn, 2001; Black \& Weiss, 1992; Horn, 1987), and level of competitive trait anxiety (Kenow \& Williams, 1992; Williams, Jerome, Kenow, Rogers, \& Sartain, 2003) through the course of a season. As athletes receive information about their competence or ability via coaching feedback, the cycle progresses to the fourth step. The final stage in the EPP completes the self-fulfilling prophecy. The last step involves the athlete changing behavior and performances to conform to the coach's original expectation. Once the athlete's behavior changes, the athlete confirms to the coach that original expectations were accurate. The coach may develop a false sense of judging ability and begin to believe that he or she is an accurate judge of talent and may intensify the self-fulfilling prophecy within the team.

The expectancy effect within athletics is documented, but according to Horn and colleagues (2006), not all coaches or athletes are susceptible to expectation formation affects. A secondary issue is the growing discourse between male and female coaches crossing coaching gender lines (e.g., males coaching females). Male and female athletes have unique characteristics across a variety of constructs (e.g., motivation to play (Duda, 1989), perceptions of athletic competence (Hollembeak \& Amorose, 2005), and preference for coaching behaviors (Fasting \& Pfister, 2000; Martin, Rocca, Cayanus, \& Weber, 2009). Specific types of coaching behaviors needed to foster an environment for intrinsic growth for males and females should be considered independently. Female sports participation is growing rapidly despite dropout rates (Ohio University, 2017; Olympic Movement, 2014); however, the increase in female athletes does not translate to an increase in female coaches or the research examining same or different gender coaches.

Interest in college softball is on the rise in the United States. The National Collegiate Athletic Association (NCAA, 2017) reports just within Division I universities, institutions have added 42 teams and 1,448 softball athletes over the past 17 years. Over the course of four years, ESPN has moved from covering 80 collegiate games (Volner, 2014) to 
over 600 games (Balf, 2017). Additionally, since 2015, the Women's College World Series (WCWS) average viewership across the final three-game championship has increased by 535,000 viewers. For the first time since the WCWS first broadcast, the WCWS final series drew an average of 440,000 more viewers than the men's baseball College World Series (CWS) in the spring 2017 across major sport media outlets (Pucci, 2017; Volner, 2017). However, more than $31 \%$ of female collegiate teams are coached by male coaches with close to $50 \%$ of Division I softball coaches being male (The Tucker Center for Research on Girls \& Women in Sport, 2014). Considering this imbalance, it is important to examine how female athletes perceive coaching behaviors and treatment. The sport of softball has a long history (Athnet, 2014), consists of large numbers of female athletes per team, is rapidly growing in popularity (Flynn, 1995), yet has not been isolated for research. These athletes' perspectives could provide insight of this generation of athletes for coaches of female athletes starting with the Division I level. SFP's are understudied in the athletic setting; yet, researchers in other fields understand the need for training and using an SFP to produce positive results (Chadha \& Narula, 2016; Eden, 2002, 2016; Eden et al., 2000; Reynolds, 2007; Tierney \& Farmer, 2004). Additionally, studies around the SFP in athletics are mostly quantitative (Amorose \& Weiss, 1998; Buning, 2016; Sinclair \& Vealy, 1989; Solomon, 2010; Solomon et al., 1998a, 1998b; Solomon, 2008a, 2008b; Weaver et al., 2016 ) with some qualitative perspectives (Siekanska et al., 2013; Solomon \& Rhea, 2008), but only capture one side of the problem. Considering these variables, the purpose of this study was to offer a mixed-methods study to shed more light on how coaching behaviors are perceived by softball athletes with coach-assigned playing expectations This study focused on step two of the EPP and offers a more holistic examination from Division I female softball athletes. The goal is to provide insight that could assist others in developing training for coaches in awareness and methods to harness the SFP.

\section{Methods}

This mixed-methods study followed a concurrent triangulation design involving survey and interview data. This study aimed to answer the research question: How do athletes with varying levels of performance abilities differ in perception of coaching behavior? Guided by EPP, it was hypothesized athletes rated as high expectancy athletes would perceive more positive coaching behaviors than athletes rated lower. The intention of this study was to contribute to the existing literature on coaching behaviors, and to provide transferable results to participants in the target population. A mixed-methods design was employed to gather a holistic perspective of participants' views on coaching behavior and treatment. Qualitative findings enhanced qualitative reports by providing context and further 
insight through specific, real-life examples.

\section{Participants}

Random cluster sampling was used to select 20 Division I softball coaches and teams from the population $(N=292)$ resulting in a sample that included teams $(n$ $=20$ ) representing 15 of the 31 Division I conferences recognized by the NCAA in 2012 (Table 1). Teams were selected from a public website listing all NCAA sanctioned Division 1 teams.

Coaches. Coaches $(n=20)$ ranged between 25 to over 60 years old, but the majority of coaches ranged between 35 to 44 years old followed by 50 to over 60 years old and 25 to 34 years. Both male and female coaches varied on lifetime collegiate coaching experience, yet the majority had coached at their current institution for less than 10 years. Coach demographics are displayed in Table 2.

Athletes. For the quantitative analysis, the majority of female softball athletes $(n=148)$ identified as White $(n=$ 144) followed by Latina $(\mathrm{n}=20)$, Other $(n=6)$, and Black $(n=4)$. Athletes ranged in age from 18 to 22 years old ( $M$ $=19.43, S D=1.17)$. Most athletes reported between 10 to14 years of lifetime softball playing experience $(n=147)$. The majority $(n=141)$ had played for their current head coach for 12 months or less

Table 1

Division I Softball Athletic Conference Representation

\begin{tabular}{lc}
\hline Conference Name & Number of Participant Institutions \\
\hline Atlantic 10 & 1 \\
Atlantic Coast & 1 \\
Big East & 2 \\
Big Ten & 1 \\
Colonial Athletic & 3 \\
Conference USA & 1 \\
Horizon League & 1 \\
Mid-American Metro Atlantic & 1 \\
Missouri Valley & 1 \\
Northeast & 1 \\
Ohio Valley & 2 \\
Sunbelt & 2 \\
Southeastern & 1 \\
Southern & 1 \\
Patriot League & 1 \\
\hline
\end{tabular}

Note: Conferences presented for the year 2012-2013. 
Table 2

Coach Participant Demographics

\begin{tabular}{lc}
\hline$n=20$ & Frequency \\
\hline Race & 19 \\
White & 1 \\
Other & \\
Gender & 6 \\
Male & 14 \\
Female & \\
Age Range & 1 \\
$25-29$ & 3 \\
$30-34$ & 8 \\
$35-39$ & 2 \\
$40-44$ & 4 \\
$50-54$ & 1 \\
$55-59$ & 1 \\
$60+$ & \\
Total Coaching Experience (years) & 1 \\
$5-9$ & 6 \\
$10-14$ & 6 \\
$15-19$ & 7 \\
$20+$ & Years \\
Total Coaching at Institution (years) & 4 \\
$>1$ & 5 \\
$1-4$ & 6 \\
$5-9$ & 1 \\
$10-14$ & 3 \\
$15-19$ & 1 \\
$20+$ & \\
\hline
\end{tabular}

$\left(M_{\text {months }}=10.10, S D=8.93\right)$ with others having played 24 months $(n=24)$ and 36 months $(n=9)$. The response rate for athletes was $36 \%$.

Of these athletes, 38 responded to interview questions. Interviewees were predominantly White $(n=33)$ with average age of 19.79 years $(S D=1.23)$, and on average had played under the head coach for 10.74 months $(S D=10.23)$. Interview athletes represented 18 of the 20 teams selected for the study, and 
11 of the 18 teams had more than one athlete responding about the head coach. Table 3 provides more information about interview athletes.

\section{Instruments}

Coach expectations. Coach expectations were recorded through the Modified Expectancy Rating Scale (MERS;
Solomon, 2008a). Solomon (2008a) developed the MERS by modifying the Expectancy Rating Scale (ERS; Solomon, 1993) and the Solomon Expectancy Sources Scale (SESS; Solomon, 2008a). Instrument structure was tested in Becker and Wrisberg (2008). For this study, Cronbach's alpha was acceptable $(\alpha=.90)$. The MERS provided coaches

Table 3

Interview Athletes' Demographics, Team Membership and Coach-assigned Expectancy Group

\begin{tabular}{lcccccc}
\hline $\begin{array}{c}\text { Athlete } \\
(n=38)\end{array}$ & Team & Age & Race & $\begin{array}{c}\text { Months } \\
\text { Under Coach }\end{array}$ & $\begin{array}{c}\text { Coach Assigned } \\
\text { Exp Group }\end{array}$ & $\begin{array}{c}\text { Self-Assigned } \\
\text { Exp Group }\end{array}$ \\
\hline Tiffany & 1 & 18 & C & 4 & Average & Average \\
Elena* & 1 & 21 & L & 4 & High & Average \\
Hannah* & 1 & 20 & C & 4 & High & High \\
Bethany & 1 & 18 & C & 4 & Low & Average \\
Tara & 1 & 20 & C & 4 & Average & Average \\
Kayla & 2 & 20 & C & 24 & High & High \\
Melissa & 3 & 18 & C & 4 & Average & Average \\
Rosemary & 4 & 21 & C & 24 & High & Average \\
Jaclyn & 4 & 20 & C & 24 & High & Average \\
Teresa & 4 & 21 & C & 36 & High & High \\
Nesa & 4 & 22 & L & 4 & High & High \\
Tory & 4 & 18 & C & 4 & Average & Average \\
Brooke & 5 & 20 & C & 24 & High & High \\
Chloe & 5 & 21 & C & 24 & Average & High \\
Jackie & 6 & 18 & C & 4 & Average & Average \\
Jamie & 7 & 18 & C & 4 & Average & Average \\
Angela & 8 & 20 & C & 4 & Low & Average \\
Shawna & 8 & 19 & C & 12 & Low & High \\
Allison & 9 & 20 & C & 36 & Low & High \\
Jill & 9 & 20 & C & 24 & Low & High \\
Alicia & 10 & 21 & C & 24 & High & High \\
Peyton & 10 & 21 & C & 12 & Low & Low \\
Jessica & 11 & 19 & C & 24 & Low & Low \\
\hline
\end{tabular}


Table 3 Continued

\begin{tabular}{llllccc}
\hline Melinda & 12 & 22 & C & 12 & High & High \\
Sadie & 12 & 21 & $\mathrm{C}$ & 12 & High & High \\
Sara & 13 & 20 & $\mathrm{C}$ & 12 & High & High \\
Christy & 13 & 18 & $\mathrm{C}$ & 4 & Average & High \\
Ashley* & 14 & 20 & $\mathrm{C}$ & 4 & Low & Average \\
Jane* & 15 & 20 & $\mathrm{C}$ & 4 & High & High \\
Brecken* $^{*}$ & 15 & 19 & $\mathrm{~L}$ & 4 & High & High \\
Alyssa* & 15 & 21 & $\mathrm{C}$ & 4 & Average & Average \\
Rylie* & 15 & 20 & $\mathrm{C}$ & 4 & High & High \\
Nicole* & 15 & 19 & $\mathrm{C}$ & 4 & Average & High \\
Kellie & 16 & 18 & $\mathrm{C}$ & 4 & High & High \\
Tracey & 17 & 20 & $\mathrm{~B}$ & 4 & High & High \\
Ginny & 17 & 21 & $\mathrm{~L}$ & 12 & Average & High \\
Sally & 18 & 18 & $\mathrm{C}$ & 4 & Low & High \\
Colleen & 19 & 21 & $\mathrm{C}$ & 36 & Low & High \\
\hline Note Ath
\end{tabular}

Note: Athletes playing for new coaches are denoted by $(*)$. Athlete race represented by Black (B). Caucasian (C), and Latina (L). All names are pseudonyms.

with eight items assessing physical and psychological attributes for each athlete. Coaches were asked to assess each athlete's performance ability compared to similarly skilled athletes. An example question was "This athlete possesses sound softball fundamentals." Coaches were asked to respond to the degree of truth for each statement using a 5 -point Likert-type scale ranging from $1=$ Not True to $5=$ Very True. Head coaches completed an electronic version of the MERS for each athlete on the roster prior to the fall practice season (initial) and again after the fall practice season (final) allowing for three months between assessments. A grand average expectation score was calculated for each athlete by first obtaining an average score for the initial eight MERS responses followed by obtaining an average score for the final eight responses, and finally by averaging the averaged initial and final MERS scores to obtain the grand average.

\section{Perceptions of coach behavior.} Athletes completed the Coaching Behavior Assessment System Perceived Behavior Scale (CBAS-PBS; Cumming, Smith, \& Smoll, 2006). The CBAS-PBS is a modified form of the Coaching Behavior Assessment System (CBAS; Smith, Smoll, \& Curtis, 1979). The CBAS is a coach-report measure assessing coach behaviors. The CBAS-PBS is a 12 -item 
measure to capture athletes' perceptions of their coach's positive and negative behaviors. The CBAS-PBS provides a definition and example in a description of the original 12 behavioral categories from the CBAS from the athletes' perspective. Athletes indicated how often the head coach behaved as described using a 7-point Likert-type scale ranging from 1 (Never) to 7 (Almost Always). The CBAS-PBS has not been used as frequently as the CBAS, but studies report acceptable reliability (ICC $=.83$ ) (e.g., Lemonidis et al., 2014). The researcher split the CBAS into positive behaviors $(\mathrm{n}=8)$ and negative behaviors $(\mathrm{n}=4)$ based on behavioral categories. Positive behaviors were identified as reward, encouragement after mistakes, corrective instruction, keeping control, giving instructions, encouragement, organization, and general communication. Negative behaviors were identified as non-reward, punishment, corrective instruction with punishment, and ignoring mistakes. A grand average CBAS-PBS score was obtained similarly to the MERS calculations. Internal consistency was acceptable for positive behaviors (Cronbach's $\alpha=$ $.78)$ and negative behaviors $(\alpha=.74)$.

Interview protocol. Interviews consisted of 12 semi-structured, open-ended questions to add depth to the quantitative data. The first question was a grand tour question used to build rapport (Kvale \& Brinkmann, 2009), and remaining questions were designed by the researcher to directly and indirectly assess the athletes' views of their head coaches' behaviors toward athletes of different performance expectation levels. The goal of the interview was to capture a deeper understanding of how participants perceived coach treatment. To contextualize responses, one question did ask participants to self-evaluate their performance capability based on other members of the team by responding to the question, "Compared to your teammates, describe your softball playing abilities." Three experts in the field of sport psychology reviewed each interview questions to enhance content validity. Each expert had a terminal degree in the field and held extensive research agendas practicing both qualitative and quantitative methodologies. Pilot interviews were conducted using three female collegiate athletes from non-participating institutions and necessary clarifications to questions were made as needed.

\section{Procedures}

Random cluster sampling was used to select teams from the Division I softball population. During the fall practice season (August 2012), coaches were then emailed an information sheet containing a link to an electronic survey requesting demographic information and contained an electronic version of the MERS. Coaches were emailed a second email containing study information and a link to the CBAS survey to forward to all athletes on his or her. Athletes were asked to provide a university issued-email address for data-matching purposes. All participants were required to provide electronic 
consent on the first page of initial survey. After the fall practice season (December 2012), coaches were emailed a second link to the final MERS survey while athletes were emailed directly a final CBAS-PBS survey. Athletes were asked to indicate on the initial survey interest in a brief phone $(n=22)$ or email $(n=19)$ interview. The qualitative sample was the result of an emergent sample (Patton, 2002). Interviews occurred during the fall practice season. To enhance confidentiality, athletes were assigned a pseudonym and identifying information was removed.

\section{Data Analysis}

Quantitative data analysis. Following procedures from Hair and Black (2000) and Weiss and Amorose (2005), two forms of cluster analyses were used to establish expectancy groups using coached-assigned expectancy scores. Multivariate analysis of variance (MANOVA) followed by discriminant function analysis (DFA) was used to examine differences between expectancy groups (independent variable) and perceptions of coach behavior (dependent variable). All assumptions for data analysis procedures were met.

Qualitative data analysis. Inductive content analysis procedure was followed for interview data. Transcripts were read multiple times in their entirety followed by an initial coding sheet to give the researcher a starting code framework. Codes were then refined, as necessary through subsequent readings, by identify- ing convergent and divergent codes then responses were grouped according to the question asked. Finally, over-arching major and minor themes were created. Two external coders assisted to confirm validity of codes to themes. After themes were assigned, a third party assessed relating quotes and themes to assist with thematic validity (Patton, 2002). A thematic framework was developed as codes emerged that guided the analysis.

\section{Results and Findings Quantitative Results}

Data was examined both for univariate and multivariate outliers, and five cases were removed. Overall, coaches were perceived as mostly positive exhibiting positive behaviors "quite often" ( $M$ $=5.09, S D=.72)$ and negative behaviors "seldom" ( $M=2.81, S D=.87)$. Table 4 provides within group perceptions of behavior frequencies.

\section{Expectancy group formation.} Expectancy groups were formed using first Ward's clustering method to determine how many groups may be present in the data. Ward's technique indicated three groupings based on MERS ratings and was followed by k-means clustering method using three pre-determined groups. The MERS descriptors were used to label cluster groups as a score of " 1 " indicated a low expectation, " 3 " indicated an average expectation, and "5" a high expectation. Cluster analyses resulted in three distinct athlete expectancy groups: (a) high expectancy (HEx) $(n=64, M=4.59)$, (b) average expectan- 
Table 4

Expectancy Group Means and DA Coefficients for Coaching Behavior Variables

\begin{tabular}{|c|c|c|c|c|c|}
\hline & $\begin{array}{c}\text { LEx } \\
n=17 \\
\end{array}$ & $\begin{array}{c}\text { AEx } \\
n=59\end{array}$ & $\begin{array}{c}\text { Hex } \\
n=70\end{array}$ & $\begin{array}{c}\text { DA Function: } \\
\text { Detached }\end{array}$ & $\begin{array}{c}\text { DA Function: } \\
\text { Engaged }\end{array}$ \\
\hline CBAS Subscale & $\begin{array}{c}M \\
(S D)\end{array}$ & $\begin{array}{c}M \\
(S D)\end{array}$ & $\begin{array}{c}M \\
(S D)\end{array}$ & $\begin{array}{l}\text { Function Coef } \\
\text { (Structure) }\end{array}$ & $\begin{array}{c}\text { Function Coef } \\
\text { (Structure) }\end{array}$ \\
\hline Non-Reward $_{(\mathrm{n})}$ & $\begin{array}{c}3.85 \\
(0.28)\end{array}$ & $\begin{array}{c}2.97 \\
(0.13)\end{array}$ & $\begin{array}{c}2.89 \\
(0.12)\end{array}$ & $\begin{array}{c}.88 \\
(.53)\end{array}$ & $\begin{array}{l}-.48 \\
(-.35)\end{array}$ \\
\hline $\begin{array}{l}\text { Encouragement } \\
\text { After Mistakes }\end{array}$ & $\begin{array}{c}3.97 \\
(0.30)\end{array}$ & $\begin{array}{c}4.34 \\
(0.16)\end{array}$ & $\begin{array}{l}4.24 \\
(0.14\end{array}$ & $\begin{array}{l}.54 \\
(-.12)\end{array}$ & $\begin{array}{l}.27 \\
(.22)\end{array}$ \\
\hline $\begin{array}{l}\text { Corrective } \\
\text { Instruction }\end{array}$ & $\begin{array}{c}4.71 \\
(.027)\end{array}$ & $\begin{array}{c}5.44 \\
(0.15)\end{array}$ & $\begin{array}{l}5.38 \\
(0.12\end{array}$ & $\begin{array}{l}-.59 \\
(-.33)\end{array}$ & $\begin{array}{l}.12 \\
(.37)\end{array}$ \\
\hline Ignore Mistakes $_{(\mathrm{n})}$ & $\begin{array}{c}2.97 \\
(0.31)\end{array}$ & $\begin{array}{c}2.80 \\
(0.14)\end{array}$ & $\begin{array}{c}2.94 \\
(0.14)\end{array}$ & $\begin{array}{l}-.47 \\
(-.01)\end{array}$ & $\begin{array}{c}.14 \\
(-.17)\end{array}$ \\
\hline \multicolumn{6}{|l|}{ General } \\
\hline Communication $_{(\mathrm{p})}$ & $\begin{array}{c}4.76 \\
(0.24)\end{array}$ & $\begin{array}{c}5.41 \\
(0.13)\end{array}$ & $\begin{array}{c}5.50 \\
(0.12)\end{array}$ & $\begin{array}{l}-.42 \\
(-.43)\end{array}$ & $\begin{array}{l}-.05 \\
(.21)\end{array}$ \\
\hline Organization $_{(\mathrm{p})}$ & $\begin{array}{c}5.85 \\
(0.20)\end{array}$ & $\begin{array}{c}6.21 \\
(0.11)\end{array}$ & $\begin{array}{c}5.83 \\
(0.12)\end{array}$ & $\begin{array}{l}.54 \\
(.09)\end{array}$ & $\begin{array}{l}.65 \\
(.59)\end{array}$ \\
\hline Punishment $_{(\mathrm{n})}$ & $\begin{array}{c}3.26 \\
(0.28)\end{array}$ & $\begin{array}{c}3.03 \\
(0.14)\end{array}$ & $\begin{array}{c}2.80 \\
(0.14)\end{array}$ & $\begin{array}{l}.40 \\
(.27)\end{array}$ & $\begin{array}{l}.49 \\
(.13)\end{array}$ \\
\hline $\begin{array}{l}\text { Corrective Inst. \& } \\
\text { Punishment }_{(\mathrm{n})}\end{array}$ & $\begin{array}{c}2.29 \\
(0.31)\end{array}$ & $\begin{array}{c}2.43 \\
(0.15)\end{array}$ & $\begin{array}{c}2.34 \\
(0.15)\end{array}$ & $\begin{array}{l}-.28 \\
(.00)\end{array}$ & $\begin{array}{l}.44 \\
(.19)\end{array}$ \\
\hline $\operatorname{Reward}_{(\mathrm{p})}$ & $\begin{array}{c}4.18 \\
(0.26)\end{array}$ & $\begin{array}{c}4.75 \\
(0.14)\end{array}$ & $\begin{array}{c}4.86 \\
(0.12)\end{array}$ & $\begin{array}{l}-.14 \\
(-.39)\end{array}$ & $\begin{array}{l}-.39 \\
(.14)\end{array}$ \\
\hline Keeping Control $_{(\mathrm{p})}$ & $\begin{array}{c}4.50 \\
(0.25)\end{array}$ & $\begin{array}{c}4.39 \\
(0.16)\end{array}$ & $\begin{array}{c}4.53 \\
(0.12)\end{array}$ & $\begin{array}{l}.02 \\
(-.05)\end{array}$ & $\begin{array}{l}-.36 \\
(-.23)\end{array}$ \\
\hline Instructions $_{(\mathrm{p})}$ & $\begin{array}{c}5.21 \\
(0.24)\end{array}$ & $\begin{array}{c}5.63 \\
(0.14)\end{array}$ & $\begin{array}{c}5.30 \\
(0.14)\end{array}$ & $\begin{array}{c}.26 \\
(.01)\end{array}$ & $\begin{array}{l}.25 \\
(.49)\end{array}$ \\
\hline Encouragement $_{(\mathrm{p})}$ & $\begin{array}{c}4.68 \\
(0.22)\end{array}$ & $\begin{array}{r}5.32 \\
(0.14) \\
\end{array}$ & $\begin{array}{c}5.22 \\
(0.13)\end{array}$ & $\begin{array}{l}-.02 \\
(-.27)\end{array}$ & $\begin{array}{l}.22 \\
(.35)\end{array}$ \\
\hline Positive Behaviors & $\begin{array}{c}4.73 \\
(0.15)\end{array}$ & $\begin{array}{c}5.17 \\
(0.09)\end{array}$ & $\begin{array}{c}5.11 \\
(0.09)\end{array}$ & & \\
\hline Negative Behaviors & $\begin{array}{c}3.10 \\
(0.20)\end{array}$ & $\begin{array}{c}2.81 \\
(0.12)\end{array}$ & $\begin{array}{c}2.74 \\
(0.10)\end{array}$ & & \\
\hline
\end{tabular}

Note: Subscripts denote inclusion in positive(p) or negative(n) behavior group. CBAS response selections ranged from 1 (never), 2 (hardly ever), 3 (seldom), 4 (sometimes), 5 (quite often), 6 (very often), and 7 (almost always). Standardized function coefficients reported. 
cy (AEx) $(n=66, M=3.73)$, and (c) low expectancy (LEx) $(n=18, M=2.60)$.

Considering the limitations of cluster analysis (Tan, Steinbach, \& Kumar, 2013), a one-way analysis of variance confirmed a significant difference between expectancy group MERS scores, Welch's $F(2,44.10)=281.20, p=.00$, $\omega^{2}=.79$, and a Games-Howell post hoc analysis confirmed LEx MERS scores were significantly lower than HEx and AEx scores, $p=.00$, and HEx scores were significantly higher than LEx and AEx scores, $p=.00$.

\section{Expectancy group differences. A} one-way MANOVA followed by DFA was used to examine differences in perceptions of coaching behavior by expectancy group. Pillai's trace revealed a significant effect of expectancy group membership on perceptions of coaching behavior with observed power $=.70$, $V=.30, F(24,266)=1.98, p=.01, \eta^{2}$ $=.15$, and DFA revealed two discriminant functions. The first accounted for $70.3 \%$ of the variance, canonical $\mathrm{R}^{2}=$ .21 , whereas the second accounted for $29.7 \%$, canonical $\mathrm{R}^{2}=.10$. In combination, these functions significantly differentiated the groups, $\lambda=.72, \chi^{2}(24)=$ $45.69, p=.01$. Removing the first function indicated the second function did not significantly differentiate between groups, $\lambda=.90, \chi^{2}(11)=14.82, p=.22$. Using structure matrix coefficients, correlations between functions and behaviors revealed the first function was most strongly correlated with more frequent non-rewarding behavior $(r=.53)$, infre- quent general communication $(r=-.43)$, and infrequent rewarding behavior $(r=$ -.39). This function was labeled detached as the most strongly correlated behaviors represented a coach that did not engage with the athletes. The second function, labeled engaged, most strongly correlated with coaching behaviors of organization $(r=.59)$, instructions $(r=.49)$, corrective instruction $(r=.37)$, and encouragement $(r=.35)$. The DFA plot (see Figure 1) showed the detached function discriminated LEx and AEx athletes from HEx athletes as HEx athletes perceived less detached behaviors. The second function discriminated the AEx athletes as perceiving more engaged behaviors than both LEx and AEx athletes. Table 4 displays function and structure coefficients for each function. Overall, DFA suggested the differences in perception of coaching behavior by expectancy group was best explained by one underlying dimension, that being perceptions of detached coaching behavior. The second dimension, perceptions of engaging behavior, influenced this primary underlying dimension, but did not necessarily change by expectancy group membership by itself.

\section{Qualitative Findings}

Of the 20 teams recruited for the study, 18 teams were represented for the qualitative portion. Two teams had first year head coaches and responses about new (to the athletes) head coaches accounted for $26 \%$ of interview responses. Three teams had five athletes per team 


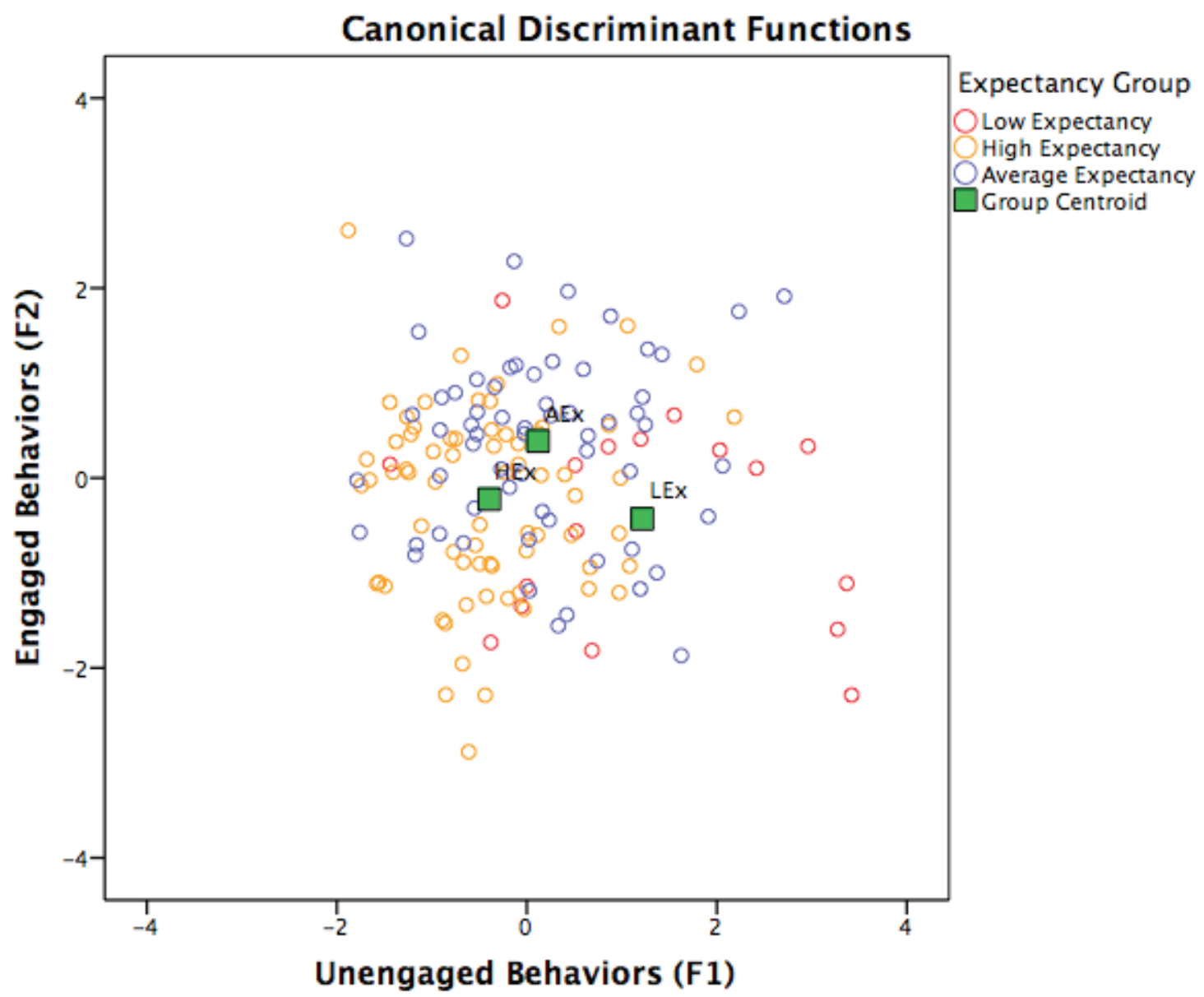

Figure 1: Expectancy Group Centroid Position by Function

participate and account for $39.5 \%$ of the total responses. The remaining 15 teams combined provided $60.5 \%$ of the total participation. Athletes were first asked to self-rate their performance expectation group (i.e., high, low, average), and comparisons of coaching behavior toward other types of athletes were used in reference to the athlete's self-identification (see Table 2).

Seventy-six percent $(n=29)$ of interviewed athletes reported noticeable differences in coach behavior directed toward the "better" players versus "weaker" players on respective teams.
Two major themes emerged pertaining to distinct coaching differences: (a) Stronger athletes get more, and (b) weaker athletes are different. Themes were considered major themes if at least $60 \%$ of participants contributed to the theme. Both major themes contained minor themes. Minor themes were retained if at least $30 \%$ of participants contributed to the theme.

\section{Stronger athletes get more (Ma-} jor 1). This major theme was defined as specific behaviors issued by the coach perceived to occur because the receiving athletes were considered to be stron- 
ger athletes on the team and was mentioned by $81.6 \%$ of athletes $(n=31)$. Two minor themes indicated stronger athletes benefited from (i) Higher standards: More attention and "pushing," or (ii) received more instruction, praise, or patience.

Higher standards: Attention and push (Minor 1i). Stronger athletes were perceived to receive more attention, or more pushing to perform, than other athletes and were held to an overall higher standard. Athletes $(n=19)$ noticed coaches providing attention only to the athletes that played starting roles. Peyton explained, "I think [coach] just cares if the starters get better. At practice she only pays attention to starters and only works on starters." Other athletes simply noticed the coach paying more attention to the athletes who served in a starting role. Hannah revealed why she thought stronger athletes were pushed more when she explained, "Sometimes [coach] will push players harder, verbally. I think she feels like the better players can handle it and will benefit from it more." Melinda agreed with Hannah and exemplified what other athletes perceived about stronger athletes when she commented that her coach "pushes them to make better plays" while Jackie noted stronger players are "different in the fact that [coaches] test and are harder on those they expect more out of."

Some athletes were not able to describe exactly why they thought stronger athletes received different behaviors, and they did not think the coach was nega- tive, but they knew those athletes were held to a generally higher standard than the rest.

Ashley's perspective was shared by most athletes under this theme,

I guess you can tell if you do something that another players does with ease, and you it's something that you do every now and then, and you're praised for that. I guess you can kind of assume that your expectations are lower than the expectations that your coach might have for that other player.

Several athletes perceived stronger athletes were placed in more prestigious team roles (e.g., mentors, performance exemplars, leaders) or had "better" relationships with the coach. Brooke, a stronger athlete, believed her coach "has confidence in everyone, but she expects us [stronger athletes] to be leaders and role models." Christy, a weaker athlete, confirmed Brooke's perceptions by explaining her coach "uses [stronger athletes] as examples all the time." Jessica thought her coach was "more friendly" towards stronger athletes. Hannah, a strong athlete, added, "I feel like Coach values our opinions of the team and comes to us individually for insight to the team. A lot of the players on the team that are very good will see coach off the field more to talk about aspects of the team outside of playing, such as team chemistry and leadership." Tiffany, an average athlete, noticed, "In regards 
to casual conversation, the coaches talk to the best players on the team like they are on their level. When I get spoken to, I feel very inferior and low on the totem pole."

Instruction, praise, and patience (Minor 1ii). Athletes $(n=12)$ shared their perceptions of stronger athletes receiving more instruction time, more praise feedback, and more patience. Colleen, a self-rated strong athlete, provided one example when she commented on the use of individual coaching and video instruction, "I mean the starters will get video reviews from the game. So yeah, I guess there is a little more coaching directed to the people who play more... there's more one-on-one time." Other athletes remarked on the coach's patience level with stronger athletes when mistakes were made on the field. Tiffany (average athlete) noticed, "When the best people on the team mess up, the coach lets it go." Ginny considered herself to be a strong athlete and consented, "He is harder on us, but he also lets us get away with a little more sometimes." While athletes noticed stronger athletes received remarks in the form of "good job" or "positive affirmation," Peyton provided insight from a self-rated weaker athlete,

Basically when we were playing [a lower division college] [Coach] said that after the game we won by a lot and she [coach] was like, 'Thankfully the starters got us up ahead enough so that we could put everybody else in.' which just makes people feel like garbage because you know we're not good enough to play against a [lower division] college.

In general, athletes believed the praise was abundant for stronger athletes as they seemed to receive praise "pretty much every time they make not even that good of a play."

Weaker athletes are different (Major 2). This theme was defined as specific behaviors issued by the coach perceived to occur because the receiving athletes were considered to be weaker athletes on the team and was mentioned by $63.2 \%$ of athletes $(n=24)$. Two minor themes indicated weaker athletes experienced (i) lower expectations: more frustration, ignoring of mistakes, or general negativity from the coach, or (ii) received more instruction or encouragement.

\section{Instruction or encouragement} (Minor 2i). Athletes $(n=15)$ contributing to this major theme perceived the coach to provide more skill instruction or encouraging feedback to weaker athletes; however, the consensus was weaker athletes needed the additional instruction and feedback. Kayla and Bethany's remarks captured the essence of this theme. Kayla, a self-rated stronger athlete, provided an example of this theme, "I mean if you're not the best and you need a lot of work he'll like maybe be on you more to get things right." Bethany, a self-rated weaker athlete, provided the explanation for increased instruction because weaker athletes "might need a little more attention in some areas." 
Lower expectations: Negativity, frustration, and ignoring (Minor 2ii). Athletes $(n=9)$ contributing to this major theme perceived the coach to exhibit negative behavior including frustration and ignoring of mistakes toward weaker athletes on the team. Alicia, a self-rated stronger athlete, noticed, "Coach tends to not pay as much attention to the weaker players than to the stronger ones." Melinda agreed when she stated, "Most of the time [our coach] just ignores them." Ashley, a weaker athlete, noticed her coach reached a point of frustration with other weaker athletes including her more quickly. After not performing a skill correctly after instruction, Ashley's coach yelled, "Why aren't you just doing what we just told you to do?" Other athletes made remarks about lower expectancy athletes during games, "If you're on the bench she doesn't always acknowledge what you're doing to help the team." Some perceived weaker athletes were treated as having a lower performance expectation in general. Athletes were unclear why they perceived this treatment but knew there was something different about the coach's behaviors. Chloe provided an example when she noticed one teammate "can't keep up with the rest of us" and her coach would correct her infrequently because the coach "doesn't really waster her time to get on her."

In summary, inductive examination of interview data revealed two major themes: (a) stronger athletes get more, and (b) weaker athletes are different. Athletes perceived teammates to have different skill levels, and coaches treated above average and below average athletes differently. Stronger athletes were perceived to be held to an overall higher expectation level involving more pushing and testing of skill limits, and received more practice time, attention, and praise than lower skilled athletes. Below average athletes' performances, presence, or mistakes were ignored more often, and lesser skilled athletes were held to an overall lower expectation.

\section{Discussion}

This mixed-methods study sought to explore how athletes of different expected performance levels perceived head coach behavior to understand more about a self-fulfilling prophecy within sports. Using coach-assigned performance expectation ratings, quantitative data showed low and average expectancy athletes perceived more behaviors reflecting a detached coach than high expectancy athletes thus supporting the null hypothesis. Despite coaches receiving positive behavior ratings, qualitative findings enhanced quantitative data that athletes of differing skill levels experienced disparate behaviors. The results are discussed in relation to an expectancy effect.

Research on coach expectations, although inconsistent, has shown high expectancy athletes can receive more instruction, praise, and encouragement than low expectancy athletes (Amorose \& Weiss, 1998; Krane, Eklund, \& McDermott, 1991; Solomon, 2008a; Sol- 
omon et al., 1998a, 1998b; Solomon \& Rhea, 2008), and is demonstrated most distinctly in the second step of the EPP. Despite an overall group of positive coaches involved in this study, HEx athletes experienced less "detached" behavior, and interview responses supported this finding with $65 \%$ of participants indicating athletes perceived differential treatment toward different levels of athletes based solely on performance ability. Specifically, LEx and AEx athletes perceived coaches ignored effort and good performances more often (non-reward), engaged in less general communication, and provided less reward and corrective instruction than with HEx athletes. These findings support literature that low expectancy athletes receive less overall feedback (Siekanska et al., 2013; Solomon, 1998, 2008). Some difference in behavior was seemingly positive in that coaches were perceived in some cases to offer more instruction or praise to below average athletes. However, as Horn (1984) demonstrated, even this type of differentiated treatment can lead to negative athlete outcomes. What is not clear is if these coaches started a self-fulfilling or a self-sustaining prophecy. Many of these athletes had been recruited by head coaches and invited to play for the current team, so an assumption could be coaches had an inaccurate initial belief they did not change, or athletes had since conformed to the coaches' initial behavior. What is unsettling is despite coaches being rated as positive behavior coaches, athletes still perceived a difference in treatment. The most alarming difference was how coaches were perceived to ignore below average athletes' performance or behavior more often than others.

Horn et al. (2006) argued a SFP could occur if coaches consistently portrayed certain behaviors toward athletes over an extended length of time, and if feedback or behaviors were negative (i.e., a Golem effect), athletes could experience harmful psychological effects. Qualitative findings revealed athletes perceived below average teammates experienced ignoring behaviors the most by the coach ignoring physical presence, mistakes, or performance attempts. Coaches were perceived to avoid interaction with these athletes including spending less practice time with this group. A Golem effect could be in motion with this sample as coaches who ignore athletes' performances or physical presence may hinder the athletes' psychological and performance growth (Horn et al., 2006). Responses in this study indicate ignoring behaviors directed at below average teammates influenced not just the targeted athlete but also their teammates. The literature is clear that negative coaching behaviors, primarily ignoring behaviors, alters the perception of team climate (e.g., task versus ego) and in turn can lead to changes in athletes' self-determined motivation, performance, and persistence (Horn et al., 2006; Ryan \& Deci, 2000; Smith, Fry, Ethington, \& Li, 2005). Additionally, ignoring behavior and excluding an athlete from the team (or not engaging) is a form of social ostracism (Williams, 
2007). Social ostracism can lead to negative physiological reactions (e.g., higher stress levels and increased blood pressure) (Stroud, Tanofsky-Kraff, Wilfley, \& Salovey, 2000). More importantly, social ostracism leads to a host of negative psychological responses including increased sense of loneliness, helplessness, frustration, anxiety, depression (Williams \& Sommer, 1997; Williams \& Zadro, 2001), and can lead the ignored to self-evaluate negatively (Williams, Bernieri, Faulkner, Gada-Jain, \& Grahe, 2000). Ultimately, if coaches ignored those athletes rated lower, a Golem effect could be set into motion with the risk of those athletes not meeting their optimal performance level, quitting the sport, or suffering more intense side effects associated with ostracism (Williams, Jerome, Kenow, Rogers, \& Sartain, 2000). This generation of athletes have made it clear that acknowledgement of physical presence and performance through either verbal or nonverbal cues is not only needed but desired for improved motivation, confidence, and ultimately, performance (Buning, 2016; Fasting \& Pfister, 2000; Horn, Bloom, Berglund, \& Packard, 2011; Norman \& French, 2013).

Particularly among females, athletes who already have a lower sense of self-confidence tend to perceive the actions of the coach more negatively compared to teammates with higher self-confidence (Konter, 2009; Siekanska et al, 2013). The lower rated athletes in this study may already have self-confidence issues, and this could explain some of the negative perceptions. However, of the 38 athletes included in the qualitative portion of the study, three athletes self-rated lower than the coach and 12 self-rated higher than their coach's rating of their performance. Of those 12 athletes, five athletes thought they were above average, yet their coach rated them below average. Overall, the qualitative sample appeared to be a group of predominantly self-assured athletes as only two athletes self-rated as below average athletes. Interestingly, little research could be found addressing the consequences of coach perceptions not aligned with athlete perceptions. Of the few studies, misalignment may be more common than exposed in the literature and should be considered for intervention strategies aimed at enhancing the coach-athlete relationship (Boyce, Gano-Overway, \& Campbell, 2009; Møllerløkken, Lorås, \& Pedersen, 2017). The question arises as to how, if at all, the misaligned expectation beliefs contribute to a SFP.

It is known that athletes can interpret coaching behaviors differently within the same team particularly based on the current success of the team (Smith, Shoda, Cumming, \& Smoll, 2009), and team success was not a factor in this study. Additionally, coach leadership style was not accounted for in this study. It is well-documented that coaches with a more democratic approach and emphasis on task-mastery are perceived to emphasize more positive behaviors (Amorose \& Horn, 2000; Hollembeak \& Amorose, 2005; Smith et al., 2010). Similarly, what 
was not measured, but deserves mention, is the motivation and teaching efficacy of the head coaches. Coaches who are highly motivated and report feeling confident in their teaching ability tend to give more positive feedback and instruction (Sullivan \& Kent, 2003). In turn, athletes who play for high-efficacy coaches perceive their coaches more favorably resulting in higher win percentages (Myers, Vargas-Tonsing, \& Feltz, 2005). More specifically, when athletes perceive a coach to be effective in teaching technique, athletes' self-efficacy can be raised producing better performance (Feltz, Chase, Moritz, \& Sullivan, 1999). Coaches in this study may vary in various elements of coaching efficacy, and coach behavior (and initial belief) could be dictated by the coach's coaching efficacy orientation rather than the athlete's actions. In experimental studies, self-efficacy has been shown to be a mediating variable to the Pygmalion effect (Eden 1990; 1996) and could be a mediator for coaches as well. More needs to be studied about the intersection between coach efficacy and prophecies. Coaches may have good intentions to behave and create desirable climates, but lack of teaching skills or efficacy could dictate how athletes perceive reality (Smith, Quested, Appleton, \& Duda, 2016a; Werthner \& Trudel, 2006). Finally, this study took into consideration average-rated athletes (AEx). Many studies are limited to the examination of only high versus low expectancy athletes; however, average athletes comprise the majority of a team. There is some ev- idence that AEx athletes may perceive behaviors similarly to LEx athletes yet not as positively as HEx athletes (Buning, 2016).

\section{Conclusion}

This study provided evidence that despite coaches being rated as exhibiting predominately positive coaching behavior, there were observed differences in behavior across expectancy groups leaving open the possibility of both a Pygmalion and Golem effect in action. The consequences of poor coaching behaviors can be detrimental to psychological well-being (Gearity \& Murray, 2010) and performance (Gould et al., 1999). In addition to the undesirable products of a negative team environment, coaches should be concerned that athletes still perceived differential behaviors between athletes even though coaches were given high scores for positive behaviors overall. Athletes' perceptions of an experience are vitally important to their motivational drive (Amorose \& Horn, 2000; Pensgaard \& Roberts, 2002), perceived motivational climate (Smith et al., 2005), achievement strategies and behavior (Treasure, 1997), and continued sport participation (Ryan \& Deci, 2000).

\section{Implications. To truly support} coaches in their quest to create optimal environments, and minimize opportunities for negative consequences (e.g., Golem effects), there needs to be a more holistic and comprehensive examination of the existing environment rather than a narrow focus (e.g., athlete-only) (Smith et 
al., 2016b). This approach should extend to include assisting coaches in their development and understanding of athlete issues surrounding the coach-athlete relationship. Coaches need assistance to understand the value of athlete perceptions, and programming should continue to help coaches understand the disconnect between how they think they are behaving and how athletes perceive behavior (Krane et al., 1991). Horn et al. (2006) provides an outline of behaviors that may be considered "Pygmalion prone" coaches verses "non-Pygmalion-prone," (p. 99), but the Pygmalion effect is a positive cycle that may be used for good. The Golem effect is the concern for coaches. Additionally, the idea that some coaches may be "Pygmalion prone," or "non-Pygmalion-prone," may have flaws as ultimately the assessment of coach behaviors relies on how athletes perceive the coach at the moment. Coaches must first be made aware of their behaviors and be open to evaluation and change. To encourage a Pygmalion effect, coaches need to raise their own expectations first. Support professionals (e.g., sport psychologists, mental performance coaches, counselors) can help coaches self-evaluate and receive consultation and training to assist with the development of coaching efficacy (Boardley, Kavussanu, \& Ring, 2008).

\section{Limitations and Future Research.} As with all research studies, there are many limitations to consider when interpreting results. Although not all lim- itations can be addressed, a few specific limitations to consider pertaining to this study are as follows: This study was part of a dissertation study and was delimited to Division I collegiate softball athletes in an attempt to get a better understanding of how this population functions. Results for the low expectancy group should be interpreted with caution as this group consisted of only 18 athletes although findings were consistent with literature (Amorose \& Weiss, 1998; Solomon, 2008a; Solomon \& Rhea, 2008). The data is five years old, and time should be considered for interpretation. The researcher altered the scoring of the CBAS-PBS by grouping and assigning a positive and negative behavior score, and although methods were strategically considered and researched, this may have affected scale reliability and validity. Additional studies using the same technique are warranted to truly determine the influence of this decision. Although the researcher intentionally studied one subset of female sports (Division I softball), findings may not represent other female sports or other competition levels (e.g., Division II). Finally, interview athletes responded through two different modes (phone vs. email). Although both modes are considered acceptable for data collection (Gaiser \& Schreiner, 2009), data may have been more consistent using one mode and collecting data from participants on more than one occasion. More research needs to be conducted to determine if the expectancy effect works consistently on both males and females (Kierein \& 
Gold, 2000). Research needs to continue with the SFP within naturalistic settings, and specifically within sports teams.

\section{References}

Amorose, A. J. (2003). Reflected appraisals and perceived importance of significant others' appraisals as predictors of college athletes' self-perceptions of competence. Research Quarterly for Exercise and Sport, 74, 60-70. doi: 10.1080/02701367.2003.10609065

Amorose, A.J., \& Horn, T.S. (2000). Intrinsic motivation: Relationships with collegiate athletes' gender, scholarship status, and perceptions of their coaches' behaviour. Journal of Sport \& Exercise Psychology, 22, 63-84. doi: 10.1123/jsep.22.1.63

Amorose, A. J., \& Horn, T. S. (2001). Pre- to post-season changes in the intrinsic motivation of first year college athletes: Relationships with coaching behavior and scholarship status. Journal of Applied Sport Psychology, 13, 355-373. doi: 10.1080.104132001753226247

Amorose, A. J., \& Weiss, M. R. (1998). Coaching feedback as a source of information about perceptions of ability: A developmental examination. Journal of Sport \& Exercise Psychology, 20, 395-420. doi: 10.1123/ jsep.20.4.395

Athnet. (2014). History of softball. Athnet: Get recruited to play college sports. Retrieved from http://www.athleticscholarships.net/
Balf, C. (2017, February 1). More than 600 college softball games will air on ESPN networks this season. Excelle Sports. Retrieved from www.excellesports.com Becker, A. J., \& Wrisberg, C. A. (2008). Affective coaching in action: Observations of legendary collegiate basketball coach Pat Summitt. The Sport Psychologist, 22, 197-211. doi: 10.1123/ tsp.22.2.197

Black, J. S., \& Weiss, M. R. (1992). The relationship among perceived coaching behaviors, perceptions of ability, and motivation in competitive agegroup swimmers. Journal of Sport \& Exercise Psychology, 14(3), 309-325. doi: 10.1123/jsep.14.3.309

Bloom, G. A., Crumpton, R., \& Anderson, J. E. (1999). A systematic observation study of the teaching behaviors of an expert basketball coach. The Sport Psychologist, 11, 157-170. doi: 10.1123/tsp.13.2.157

Boardley, D., Kavussanu, M., \& Ring, C. (2008). Athletes' perceptions of coaching effectiveness and athlete-related outcomes in Rugby Union: An investigation based on the coaching efficacy model. The Sport Psychologist, 29, 269-287. doi: 10.1123/ tsp.22.3.269

Boyce, B. A., Gano-Overway, L. A., \& Campbell, A. L. (2009). Perceived motivational climate's influence on goal orientations, perceived competence, and practice strategies across the athletic season. Journal of Applied Sport Psychology, 21, 381-394. doi: 10.1080.10413200903204887 
Buning, M. M. (2016). The relationship between coach expectations and female softball athletes' motivation and perceptions of coach behavior. Women in Sport and Physical Activity, 24, 43-53. doi: 10.1123/wspaj.2014-0056

Chadha, N., \& Narula, B. (2016). Pygmalion effect: Fostering performance among adolescents. Educational Quest, 7(1), 1-4.

Christakis, N. A. (1999). The self-fulfilling prophecy. Death foretold: Prophecy and prognosis in medical care (pp. 135162). Chicago, IL: University of Chicago Press.

Clark, E. L. (1927). The value of student interviewers. Journal of Personnel Research, 5, 204-207.

Cumming, S. P., Smith, R. E., \& Smoll, F. L. (2006). Athlete-perceived coaching behaviors: Relating two measurement traditions. Journal of Sport and Exercise Psychology, 28, 205-213. doi: 10.1123/ jsep.28.2.205

Davidson, O. B., \& Eden, D. (2000). Remedial self-fulfilling prophecy: Two field experiments to prevent Golem Effects among disadvantaged women. Journal of Applied Psychology, 83(3), 386-398. doi: 10.1037/00219010.85.3.386

Duda, J. (1989). Relationship between task and ego orientation and perceived purpose of sport among high school athletes. Journal of Sport \& Exercise Psychology, 11, 318-335. doi: 10.1123/jsep.11.3.318

Eden, D. (1990). Industrialization as a self-fulfilling prophecy: The role of expectations in development. International Journal of Psychology, 25, 871-886. doi: 10.1080/00207599008247933 Eden, D., (1996). From self-efficacy to means efficacy: Internal and external sources of general and specific efficacy. Paper presented at the $56^{\text {th }}$ annual meeting of the Academy of Management (Organizational Behavior Division), Cincinnati, $\mathrm{OH}$.

Eden, D. (2002). Self-fulfilling prophecies in organizations. In L. Stroh, G. Northcraft, \& M. Neale (Eds.), Organizational Behavior: A Management Challenge (3rd ed.) (pp. 87-117). Mahwah, NJ: Lawrence Erlbaum Associates, Inc.

Eden, D. (2016). Self-fulfilling prophecy and the Pygmalion Effect in management. Oxford Bibliographies. doi: 10.1093/OBO/9780799846740-0014

Eden, G., Geller, D., Gordon-Turner, R., Inbar, I., Liberman, M., Pass, Y...Shalit, M. (2000). Implanting Pygmalion leadership style through workshop training: Seven field experiments. Leadership Quarterly, 11(2), 171-210.

Eden, D., \& Shani, A. B. (1982). Pygmalion goes to boot camp: Expectancy, leadership, and trainee performance. Journal of Applied Psychology, 67(2), 194199. doi: 10.1037/0021-9010.67.2.194

Fasting, K. \& Pfister, G. (2000). Female and male coaches in the eyes of female elite soccer players. European Physical Education Review, 6(1), 91-110. doi: 10.1177/1356336X000061001 
Feltz, S. L., Chase, M. A., Moritz, S. E., \& Sullivan, P. J. (1999). A conceptual model of coaching efficacy: Preliminary investigation and instrument development. Journal of Educational Psychology, 91, 765-776. doi: 10.1037/0022-0663.91.4.765

Flynn, M. (1995). Softball slides into the 21 st Century. Parks and Recreation, 30(4), 36-42.

Gaiser, T. J., \& Schreiner, A. E. (2009). Using email for data collection. In A guide to conducting online research (pp. 37-60). Thousand Oaks, CA: Sage Publications.

Gearity, B. T., \& Murray, M. A. (2010). Athletes' experiences of the psychological affects of poor coaching. Psychology of Sport and Exercise, 12, 213-221. doi: 10.1080/17408989.2010.548061

Gladwell, M. (2008). The Matthew Effect. Outliers: The story of success (pp. 20-25). New York, NY: Little, Brown, and Company.

Gould, D., Greenleaf, C., Dieffenbach, K., Lauer, L., Chung, Y., Peterson, K., \& McCann, S. (1999). Positive and negative factors influencing US Olympic athlete and coaches: Nagano Games assessment. US Olympic Committee Sport Science and Technology Final Grant Report.

Hair, J. F., Jr., \& Black, W. C. (2000). Cluster analysis. In L. G. Grimm \& P. R. Yarnold (Eds.), Reading and understanding more multivariate statistics (pp. 147-205). Washington, DC: American Psychological Association.
Hancock, D. J., Adler, A. L. \& Côté, J. (2013). A proposed theoretical model to explain relative age effects in sport. European Journal of Sport Science, 13(6), 630-637. doi: 10.1080/17461391.2013.775352

Hollembeak, J., \& Amorose, A.J. (2005). Perceived coaching behaviors and college athletes' intrinsic motivation: A test of self-determination theory. Journal of Applied Sport Psychology, 17, 2036. doi: 10.1080/10413200590907540 Horn, T. S. (1984). Expectancy effects in the interscholastic athletic setting: Methodological considerations. Journal of Sport Psychology, 6(1), 60-76. doi: 10.1123/jsp.6.1.60

Horn, T. S. (1987). The influence of teacher-coach behavior on the psychological development of children. Advances in Pediatric Sport Sciences, 2, 121-142.

Horn, T.S., Bloom, P., Berglund, K.M., \& Packard, S. (2011). Relationship between collegiate athletes' psychological characteristics and their preferences for different types of coaching behaviour. The Sport Psychologist, 25, 190-211. doi: 10.1123/tsp.25.2.190 Horn, T. S., Lox, C., \& Labrador, F. (1998). The self-fulfilling prophecy theory: When coaches' expectations become reality. In J. M. Williams (Ed.), Applied sports psychology: Personal growth to peak (4th ed.) (pp. 82-108). Mountain View, CA: Mayfield Publishing Company.

Horn, T. S., Lox., C. L., \& Labrador, F. (2006). The self-fulfilling prophecy 
theory: When coaches' expectations become reality. In J.M. Williams \& V. Krane (7th Ed.) Applied sport psychology: Personal growth to peak performance (pp. 82-107). New York: McGraw-Hill.

Inamori, T., \& Analoui, F. (2010). Beyond Pygmalion effect: the role of managerial perception. Journal of Management Development, 29(4), 306-321.

Jowett, S., \& Cramer, D. (2010). The prediction of young athletes' physical self from perceptions of relationships with parents and coaches. Psychology of Sport \& Exercise Science, 11(2), 140-148. doi: 10.1016/j. psychsport.2009.10.001

Jussim, L., \& Harber, K. D. (2005). Teacher expectations and self-fulfilling prophecies: Knowns and unknowns, resolved and unresolved controversies. Personality and Social Psychology Review, 9(2), 131-155. doi: 10.1207/s15327957pspr0902_3 Jussim, L., Palumbo, P., Chatman, C., Madon, S., \& Smith, A. (2000). Stigma and self-fulfilling prophecies. In T.F. Heatherton, R.E. Kleck, M.R. Hebl, \& J.G. Hull (Eds.). The social psychology of stigma (pp. 374-418). New York, NY: Guilford Press.

Kahan, D. (1999). Coaching behavior: A review of the systematic observation research literature. Applied Research in Coaching and Athletics Annual, 14, 1758.

Kenow, L. J., \& Williams, J. M. (1992). Coaching behavior: A review of the systematic observation research literature The Sport Psychologist, 6, 344-357. Kierein, N. M., \& Gold, M. A. (2000). Pygmalion in work organizations: A meta-analysis. Journal of Organizational Behavior, 913-928.

Konter, E. (2009). Perceptions of soccer players about leadership powers according to their level of play. Social Behavior and Personality, 37(4), 503-512.

Krane, V., Eklund, R., \& McDermott, M. (1991, March). Collaborative action research and behavioral coaching intervention: A case study. Applied Research in Coaching and Athletics Manual, 119-147.

Kvale, S., \& Brinkmann, S. (2009). Interviews: Learning the craft of qualitative research interviewing (2nd ed.). Thousand Oaks, CA: Sage Publishing.

Lemonidis, N., Tzioumakis, Y., Karypidis, A., Michalopoulou, M., Gourgoulis, V., \& Zourbanos, N. (2014). Coaching behavior in professional baseketball: Discrepancies between players' and coaches' perceptions. Athletic Insight, 6(1), 65-80.

Lyle, J. (1999). Coaching philosophy and coaching behaviour. In N. Cross \& J. Lyle (Eds.) The coaching process: Principles and practice for sport (pp. 25-46). Oxford: Butterworth-Heineman. Martin, M.M., Rocca, K.A., Cayanus, J., \& Weber, K. (2009). Relationships between coaches' use of behaviour alteration techniques and verbal aggression on athletes' motivation and affect. Journal of Sport Behavior, 32, 227-241. 
McNatt, D. B. (2000). Ancient Pygmalion joins contemporary management: $\mathrm{A}$ meta-analysis of the result. Journal of Applied Psychology, 85(2), 314-322. doi: 10.1037/0021-9010.85.2.314

Merton, R. K. (1948). The self-fulfilling prophecy. Antioch Review, 8, 193-210.

Meyer, B., Pilkonis, P. A., Krupnick, J., L., Egan, M. K., Simmens, S. J., \& Sotsky, S. M. (2002). Treatment expectancies, patient alliance and outcome: Further analyses from the National Institute of Mental Health Treatment of Depression Collaborative Research Program. Journal of Consulting and Clinical Psychology, 70(4), 1051-1055. doi: 10.1037/0022-006x.70.4.1051

Møllerløkken, N. E., Lorås, H., \& Pedersen, A. V. (2017). A comparison of players' and coaches' perceptions of the coach-created motivational climate within youth soccer teams. Frontiers in Psychology, 8, 109. doi: 10.3389/ fpsyg.2017.00109

Myers, N. D., Vargas-Tonsing, T. M., \& Feltz, D. L. (2005). Coaching efficacy in intercollegiate coaches: Sources, coaching behavior, and team variables. Psychology of Sport and Exercise, 6, 129-143. doi: 10.1016/j. psychsport.2003.10.007

Natanovich, G., \& Eden, D. (2008). Pygmalion affects amount outreach supervisors and tutors: Extending sex generalizability. Journal of Applied Psychology, 93(6), 1382-1389. doi: 10.1037/a0012566

National Collegiate Athletic Association (NCAA, 2017). Student-athlete partici- pation 1981-82-2016-17. Indianapolis, IN: E. Irick.

Norman, L., \& French, J. (2013). Understanding how high performance women athletes experience the coach-athlete relationship. International Journal of Coaching Science, 7(1), 3-24.

Ohio University. (2017). [Graph illustrations of women's sports participation and media coverage]. The Evolution of Women's Sports. Retrieved from http:// athleticadminonline.ohio.edu/resources/infographics/the-evolutionof-womens-sports/

Olympic Movement. (2014, May). Factsheet: Women in the Olympic Movement. A report commissioned by the International Olympic Committee. Retrieved from www.olympic.org Patton, M. Q. (2002). Qualitative research and evaluation methods (3rd ed.). C. D. Laughton \& V. Novak (Eds.). Thousand Oaks, CA: Sage Publications.

Pensgaard, A. M., \& Roberts, G. C. (2002). Elite athletes' experiences of the motivational climate: the coach matters. Scandinavian Journal of Medicine \& Science in Sports, 12(1), 54-59.

Pucci, D. (2017, June 16). ESPN ratings: Oklahoma-Florida earns Women's College World Series viewership milestones. Awful Announcing. Retrieved from http:// www.awfulannouncing.com

Reynolds, D. (2007). Restraining Golem and harnessing Pygmalion in the classroom: A laboratory study of managerial expectations and task design. Academy of Management Learn- 
ing \& Education, 6(4), 475-483. doi: 10.5465/amle. 2007.2694947

Rice, S. A. (1929). Contagious bias in the interview: A methodological note. American Journal of Sociology, 35, 420423.

Rist, R. (2000). Student social class and teacher expectations: The self-fulfilling prophecy in ghetto education. Harvard Educational Review, 70(3), 257-302. doi: 10.17763/ jaer.40.3.h0m026p670k618q3

Rosenthal, R., \& Jacobson, L. (1968). Pygmalion in the classroom: Teacher expectations and pupil intellectual growth. New York, NY: Hole, Rinehart, and Winston.

Rowe, W. G., \& O'Brien, J. (2002). The role of Golem, Pygmalion, and Galatea effects on opportunistic behavior in the classroom. Journal of Management Education, 26(6), 612-628. doi: $10.1177 / 1052562902238321$

Rudman, L. A., \& Glick, P. (2008). Self-sustaining prophecies. In The social psychology of gender: How power and intimacy shape gender relations (pp. 131155). New York, NY: Guilford Publications.

Ryan, R. M., \& Deci, E. L. (2000). Self-determination theory and the facilitation of intrinsic motivation, social development, and well-being. American Psychologist, 55(1), 68-78. doi: 10.1037/0003-066X.55.1.68

Salomon, G. (1981). Self-fulfilling and self-sustaining prophecies and the behaviors that realize them. American Psychologist, 36(11), 1452-1453.
Siekanska, M., Blecharz, J., \& Wojtowicz, A. (2013). The athlete's perception of coaches' behavior towards competitors with a different sports level. Journal of Human Kinetics, 39(1), 231-242. doi: 10.2478/hukin-2013-0086

Sinclair, D. A., \& Vealey, R. S. (1989). Affects of coaches' expectations and feedback on the self-perceptions of athletes. Journal of Sport Behavior, 12, 77-91.

Smith, S. L., Fry, M. D., Ethington, C. A., \& Li, Y. (2005). The effect of female athletes' perceptions of their coaches' behaviors on their perceptions of the motivational climate. Journal of $A p$ plied Sport Psychology, 17, 170-177. doi: 10.1080/10413200590932470

Smith, A. E., Jussim, L., \& Eccles, J. (1999). Do self-fulfilling prophecies accumulate, dissipate, or remain stable over time? Journal of Personality and Social Psychology, 77(3), 548-610. doi: 10.1037/0022-3514.77.3.548

Smith, A., Ntoumanis, N., \& Duda, J. (2010). An investigation of coach behaviors, goal motives, and implementation intentions as predictors of well-being in sport. Journal of Applied Sport Psychology, 22, 17-33. doi: 10.1080/10413200903403190 Smith, N. Quested, E., Appleton, P. R., \& Duda, J. L. (2016a). Observing coach-created motivational environment across training and competition in youth sport. Journal of Sport Sciences, 35, 149-158. doi: 10.1080/02640414.2016.1159714 
Smith, R. R., Shoda, Y., Cumming, S. P., \& Smoll, F. L. (2009). Behavioral signatures at the ballpark: Intraindividual consistency of adults' situation-behavior patterns and their interpersonal consequences. Journal of Research in Personality, 43, 187-195. doi: 10.1016/j. jrp.2008.12.006

Smith, R. E., \& Smoll, F. L. (1990). Self-esteem and children's reactions to youth sport coaching: A field study of self-enhancement processes. Developmental Psychology, 26, 987-993. doi: 10.1037/0012-1649.26.6.987

Smith, F. L., \& Smoll, R. E. (2002) Coaching behavior research and intervention in youth sport. In F. L. Smith \& R. E. Smoll (Eds.) Children and youth in sport (pp. 21-231). Dubuque, IA: Kendall-Hunt.

Smith, R. E., Smoll, F. L., \& Barnett, N. P. (1995). Reduction of children's sport performance anxiety through social support and stress-reduction training for coaches. Journal of Sport Psychology, 1, 59-75. doi: 10.1016/0193-3973(95)90020-9

Smith, R. E., Smoll, F. L., \& Curtis, B. (1979). Coach effectiveness training: A cognitive-behavioral approach to enhancing relationship skills in youth sport coaches. Journal of Sport Psychology, 1, 59-75. doi: 10.1123/jsp.1.1.59 Smith, N. Tesier, D., Tzioumakis, Y., Fabra, P., Quested, E., Appleton, P. R., ...Duda, J. (2016b). The relationship between observed and perceived assessments of the coach-created motivation environment and links to athlete motivation. Psychology of Sport and Exercise, 23, 51-63. doi: 10.1016/j. psychsport.2015.11.001

Solomon, G. B. (1993). Sources of expectancy information among assistant coaches: The influence of performance and psychological cues. Journal of Sport Behavior, 25, 279-286.

Solomon, G. B. (2008a). The assessment of athletic ability in intercollegiate sport: Instrument construction and validation. International Journal of Sports Science, 3(4), 509-521. doi: 10.12.60/174795408787186477

Solomon, G. B. (2008b). Expectations and perceptions as predictors of coaches' feedback in three competitive contexts. Journal for the Study of Sports and Atbletes in Education, 2(2), 161-179. doi: 10.1179/ ssa.2008.2.2.161

Solomon, G. B. (2010). The assessment of athletic ability at the junior college level. International Journal of Sports Science \& Coaching, 5(1), 37-46. doi: 10.1260.1747-9541.5.1.37

Solomon, G. B., DiMarco, A. M., Ohlson, C. J., \& Reece, S. D. (1998a). Expectations and coaching experiences: Is more better? Journal of Sport Behavior, 21, 444-455.

Solomon, G. B., Golden, A. J., Ciapponi, T. M., \& Martin, A. D. (1998b). Coach expectations and differential feedback: Perceptual flexibility revisited. Journal of Sport Behavior, 21, 298-310. Solomon, G. B., \& Kosmitzki, C. (1996). Perceptual flexibility and differential feedback among intercollegiate bas- 
ketball coaches. Journal of Sport Behavior, 19, 163-177.

Solomon, G. B., \& Rhea, D. J. (2008). Sources of expectancy information among college coaches: A qualitative test of expectancy theory. International Journal of Sports Science and Coaching, 3, 251-268. doi: 10.1260/174795408785100725

Stroud, L. R., Tanofsky-Kraff, M., Wilfley, D. E., \& Salovey, P. (2000). The Yale Interpersonal Stressor (YPS): Affective, physiological, and behavioral responses to novel interpersonal rejection paradigm. Annals of Behavioral Medicine, 22(3), 201-213.

Sullivan, P. J., \& Kent, A. (2003). Coaching efficacy as a predictor of leadership style in intercollegiate athletics. Journal of Applied Sport Psychology, 15, 1-11. doi: 10.1080/10413200305404 Tan, P. N., Steinbach, M., \& Kumar, V. (2013). Data mining cluster analysis: Basic concepts and algorithms: Introduction to data mining (pp. 487-559). Boston, MA: Addison-Wesley.

The Tucker Center for Research on Girls \& Women in Sport. (2014, January). Head coaches of women's collegiate teams: A report on select NCAA Division-I FBS institutions, 2013-14. Minneapolis, MN: LaVoi, N. M..

Tierney, P., \& Farmer, S. M. 2004. The Pygmalion process and employee creativity. Journal of Management, 30(3), 413-432.

Treasure, D. C. (1997). Perceptions of the motivational climate and elementary school children's cognitive and affective response. Journal of Sport and Exercise Psychology, 19, 278-290.

Volner, D. (2014, January 28). ESPN rolls out unprecedented college softball schedule. ESPN MediaZone. Retrieved from http://www.espnmediazone.com.

Volner, D. (2017, June 8). Sooners' second consecutive National Championship: Mostwatched Women's College World Series finals sweep ever. ESPN MediaZone. Retrieved from http://www.espnmediazone.com.

Weaver, j. Moses, J. F., \& Snyder, M. (2016). Self-fulfilling prophecies in ability settings. The Journal of Social Psychology, 156, 179-189. doi: 10.1080/00224545.2015.1076761

Weiss, M. R., \& Amorose, A. J. (2005). Children's self-perceptions in the physical domain: Between- and within-age variability in level, accuracy, and sources of perceived competence. Journal of Sport \& Exercise Psychology, 27, 226-244. doi: 10.1123/jseop.27.2.226

Werthner, P., \& Trudel, P. (2006). A new theoretical perspective for understanding how coaches learn to coach. Sport Psychology, 20, 198-212. doi: 10.1123/tsp.20.2.198

Wilkinson, D. (2009). The self-fulfilling prophecy in intensive care. Theoretical Medicine and Bioethics, 30(6), 401-410.

Williams, K. D. (2007). Ostracism. Annual Review of Psychology, 58, 425-452.

Williams, K. D., Bernieri, F. J., Faulkner, S. J., Gada-Jain, N., \& Grahe, J. E. (2000). The Scarlet Letter study: Five days of social ostracism. Journal of Person- 
al and Interpersonal Loss, 5, 19-63. doi: 10.1080/10811440008407846

Williams, J. M., Jerome, G. J., Kenow, L., Rogers, T., \& Sartain, T. A. (2003). Factor structure of the coaching behavior questionnaire and its relationship to athlete variables. The Sport Psychologist, 17, 16-34. doi: 10.1123/ tsp.17.1.16

Williams, K. D., \& Sommer, K. L. (1997). Social ostracism by coworkers: Does rejection lead to social loafing or compensation. Personality \& Social Psychology Bulletin, 23, 693-706. doi: 10.1177/0146167297237003

Williams, K. D., \& Zadro, L. (2001). Ostracisim: On being ignored, excluded, and rejected. In M. Leary (Ed.), Interpersonal rejection (p. 21-54). New York: Oxford Press.

Wilson, M. A., \& Stephens, D. E. (2005). Great expectations: How do athletes of different expectancies attribute their perception of personal athletic performance? Journal of Sport Behavior, 28(4), 392.

White, S. S., \& Locke, E. A. (2000).

Problems with the Pygmalion affect and some proposed solutions. Leadership Quarterly, 11(3), 389-415. doi: 10.1016/S1048-9843(00)00046-1 